\title{
Discussion on the Application and Practice of Discourse Cohesion and Coherence in English-Chinese Translation
}

\author{
Jun Yan \\ Jiangsu Vocational Institute of Commerce, Nanjing Jiangsu, 211168, China
}

Key words: Cohesion; Discourse cohesion, English-Chinese translation, System-functional linguistics.

\begin{abstract}
Discourse cohesion and coherence is important in English-Chinese translation. They can not only realize the scheming of article structure but can use different means to make the entire discourse connection more appropriate. So this thesis hopes to use system-functional linguistics as theoretical research keynote to discuss the detailed application process of discourse cohesion and coherence in practical English-Chinese translation so as to highlight its superiority of its application characteristics.
\end{abstract}

\section{Introduction}

Compared with grammatical unit, discourse is the language use unit, and semantic unit. The discourse should have a mutually embodied relationship with sentences in the article. Both of them jointly reflect the real connotation of discourse, which has reflected the key standard that discourse cohesion and coherence can reflect article quality since from modern discourse. In other words, when the message sender and receiver can both clarify the practical situation of the discourse, it proves that both discourse and semantic coherence are achieved. Without doubt, discourse coherence depends on its cohesive devices. Cohesion make the grammar and vocabularies between sentences produce meaningful connection and make message receivers understand the real connotation of the discourse.

\section{Introduction of discourse cohesion and coherence in English-Chinese translation}

\section{Introduction of the fundamental connotation of "discourse analysis"}

The key of English-Chinese translation is the language which describes and explains various phenomenon in the translation process finally formed based on linguistic theory and analysis on language. High-level English-Chinese translation should connect the research on language with translation practice behavior because English-Chinese translation is not simple word-for-word translation but to add more linguistic contents so as to make the translation effect more emotional. It can be said that when translation domain is integrated with modern linguistic theory of "Discourse Analysis", translation scholars have brand new perception of the analysis on discourse context which is a process based on sensibility development from experience developed to theory. Modern English-Chinese translation work should be launched from the cohesion and coherence of discourse analysis to discuss the supposed expression form of two discourse analysis means in practical bilingual translation.

\section{Cohesion and coherence}

Discourse cohesion is a basic semantic concept representing different components in the discourse such as the internal meaning and connection between vocabularies and short sentences. The book of 
British couple logisticians M. A. K. Halliday and R. Hasan, Cohesion, has elaborated that, "discourse is a fluent phrase making both situational discourse and register achieve the objective of coherence". That is to say, the body of discourse is coherent but the foundation of its coherence lies in the correct application of cohesive devices. Both supplement each other but dispensable and exclusive with each other. It can be said that coherence is the topic development basis between sentences. Good coherence has optimize the linguistic function and expressive ability. It can reduce the coherent controversy at the same time and make the article more graceful and vivid.

Many scholars think that discourse is realized through multiple coherent devices. To be frank, it is the coherence that facilitates the discourse expression which is the core of discourse coherence, as the nature of translation is a process of semantic exchange. When translators make semantic and grammar conversion on two languages, considering two languages have their own features, the superposition of one linguistic form on another linguistic form must be completed with the help of cohesive and coherent devices so as to express unique message structure of source language during the process of semantic and discourse adjustment. This is the charm of linguistic transformation, which means that discourse coherence and many cohesive devices have achieved the acceptability and understandability after linguistic transformation ${ }^{[1]}$.

\section{Analysis on discourse coherence in English-Chinese translation}

In English-Chinese translation, there exist at least three kinds of relevance among the discourse: subject relevance, semantic relevance and context relevance. It is the existence of these three relations that guarantee the discourse coherence and integrity. Next three passages of English-Chinese translation will be used to prove the important function of these three relevance in discourse coherence.

\section{Analysis on semantic relevance in English-Chinese translation example sentences}

Thursday December 10, 2015, promised to be a marvelous day for Steven, a 23-year-old recent graduate of US-air-force-officer school. The morning mist slowly lifted over United States Air Force Academy National Park to reveal the sun blazing from a cloudless sky.

Thursday December 10, 2015, promised to be a marvelous day for Steven, a 23-year-old recent graduate of US-air-force-officer school.The morning mist slowly lifted over United States Air Force Academy National Park to reveal the sun blazing from a cloudless sky.

2015 年12月10日，星期四，美国空军学院国家公园被沐浴在明媚的阳光里，万里无云、 风和日丽，这对才走出校门的空军军官史蒂文是一个再好不过的日子。

From this section of translation between English and Chinese, we can see that word order in original English text has been greatly adjusted into target text, i.e. separating and making up again. This kind of translation tactic has reflected semantic interconnectedness to a certain degree so that the result of the translation can make the translated part in Chinese more significant and obviously connected among the discourse as appropriate translation based on semantic relevance.

\section{Analysis on topic relevance in English-Chinese translation example sentences}

Translation with topic relevance can reflect the depth of language or literature profoundness. Take Mary. E. Pearce's Polsinney Harbor as example, the novel was translated by Chinese linguist Bao Huinan with the title of Deep love for fishing port based on the plot and contents instead of directly being translated into Polsinney Harbor. The reasons is because there exist the relevance between topic and translation in English-Chinese translation, i.e. semantic expression in a deep level. Specifically, topic relevance reflects the translation property existing between discourses in accordance with the whole topic requirement in the discourse. This novel describes that a young and beautiful lady Maggie. Kay ll came to Polsinney Harbor for life reasons but was abandoned by her boyfriend when she was in trouble. Then an old fisher in Polsinney Harbor, Talak, generously helped her get out of trouble. The whole novel depicted a sad story of two men deeply in love with a beautiful 
girl with the background of the sea. If translated directly into Polsinney Harbor, it undoubtedly could not express the theme of "love" connecting the mainline of the story. Thus, it is more suitable for story plot and more attractive to readers if translated into Deep love for fishing port from the perspective of topic relevance.

\section{Analysis on context relevance in English-Chinese translation example sentences}

"All good attend you, dear old woman”, he said, embracing Peggotty, “and you too, Mas”, shaking hands with me.

\section{“亲爱的妹妹, 我祝福你。”他拥抱了博古提。“我也祝你如意, 卫少爷。”他跟我握手 说。}

This section of translation has just right reflected the context relevance with the purport that each segment in the discourse will produce contextual integration with the discourse main body. In this passage of dialogue, Mr. Pegotty met again with his sister after a long separation and gave blessings to each other affectionately. Here the translation of "old woman" into sister fit the background of source text because the sister was still a young girl but "old woman" had a meaning of teasing full of family affection. Thus, the translator's translation into "sister" can be more adapted to the connotation of original text based on the relationship between two of them and the context ${ }^{[2]}$.

\section{Analysis on classification of cohesion in English-Chinese translation}

The application of cohesive device in discourse takes up a great proportion in the article as it is the most important tool to connect sentences in the discourse. Generally in English-Chinese translation, coherence is used to express the effective coherence between vocabularies and grammar. Specific patterns of manifestation include substitution, connection, coordination and ellipsis. And lexical cohesion mainly includes synonymy, antonym, repetition and contextual semantic cohesion and collocation. Reasonably using cohesion can make the translated version under translation activity background more aesthetic and scientific.

\section{Analysis on the application of grammatical cohesive device in English-Chinese translation}

Grammar is framework of discourse. Grammatical cohesion can connect vocabularies and short sentences to guarantee semantic coherence so that the discourse appears as an integrity. Generally, grammatical cohesion is reflected as four kinds of state in translation: coordination, ellipsis, substitution and connection. Next passage will explain ellipsis and connection through example sentences.

Ellipsis

Leaving out some elements in the discourse is one of important means in grammatical cohesion. It prevents the repeated semantic occurrence so as to highlight the addition of new information. Reasonably using ellipsis can make the whole discourse closely cohesive. Hope readers can understand the whole connotation of the discourse and true profoundness of English articles. Seeing substantially, there exist substantial differences between English and Chinese in the presentation phenomenon of ellipsis because English majors in hypotaxis and can leave out some Notional Verbs through marks of mood and tense. Thus, when translating English into Chinesse, it is necessary to complete the elliptical contents. Reviewing Chinese, we find it focusing on parataxis very much so that people can often see that subject are usually omitted in an article to make readers understand which part the hidden subject refers to. Unlike Chinese, subject cannot be left out in English. Thus, it is necessary to supplement subject in English-Chinese translation.

Studies serve for delight, for ornament, and for ability.

阅读可怡情、可博采、可长才。

Above example sentence has integrated the translation of "serve" into "for delight, for ornament, and for ability", which is to use Chinese gerund to express the original meaning of serve. It is a 
grammatical cohesion ellipsis in a very literal sense, which makes the discourse simpler with aesthetics.

\section{Connection}

Connection is the most important expression connotation in grammatical cohesion to present various logical relationship in the discourse through connection. General connection is through transitional vocabularies which represent certain cause and effect, transitional, and temporal logic relationship. From the perspective of connotation, English discourse connection focuses on hypotaxis connection, i.e. vocabulary and grammar in the discourse have obvious delomorphic features of manifestation. Chinese discourse is different as it focuses on parataxis connection with more outstanding invisible features. Thus, in English-Chinese translation, some conjunctions can be omitted to the greatest extent to display the parataxis charatersitics of Chinese language as far as possible.

As the life is lke a sea,so is the living like a ship.

生命如海, 生活似舟。

In this translation, there exist English sentence pattern of “as...so...” If it is directly translated into “正如生命像大海一般博大广阔, 因此我们的生活就像是一叶泛舟, 显得如此渺小。” according to the sentence pattern, the basic requirement of parataxis in Chinese cannot be reached so that the translation is with no aesthetics. Thus, the sentence pattern "as...so..." can be directly omitted to accord with parataxis aesthetics and to make the translated version with more taste.

\section{Analysis on the application of lexical cohesive devices in English-Chinese translation}

Lexical cohesion mainly reflects the real semantic relation between each vocabulary in the discourse. They construct the corridor of article coherence with the purpose of achieving discourse coherence. During this process, firstly we should be clear that English and Chinese vocabularies are not one-to-one correspondent, and we should clarify the reconstruction task of lexical cohesion in original text. Beatify and adjust the work order in the article through rich rhetoric modes in Chinese to express the connotation of the article. Lexical cohesion mainly includes synonymy, antonym, repetition, hyponymy, and collocation.

Take hyponymy as example, it is a kid of discourse relation and meaning expressed in preceding part of the text is contained in the following part. That is to say that meaning of the preceding text belongs to one kind or one part of the meaning of the following text. Although there exist relations in hyponymy, the expression ways are not the same.

There is more to their life than political and social and economic problems, more than transient everydayness.

他们的生活问题远远不止于政治与经济，也不止是家常琐碎。

“Everydayness” is translated into “柴米油盐”. It is the Chinese hyponym translated according to English hypernym. The translation is close to life. Thus, in translation from English to Chinese, it is a must to conduct effective observation and treatment according to the context to guarantee the translated contents can express their Chinese meaning as well as accord with some expression customs in Chinese ${ }^{[3]}$.

Conclusion: Based on system-functional linguistics of M. A. K. Halliday and R. Hasan, this article mainly analyzes the example application process of discourse cohesive and coherent devices in English-Chinese translation. It can be said that coherence and cohesion are important expressive means for connecting sentences into passage. They turn discourse superficial cohesive expression into more profoundly semantic coherence, getting translation rid of one-sided sentence-to-sentence translation mentality. This makes the discourse more aesthetic and more acceptable for readers.

\section{References}

[1] Zhang Delu, Zhang Aijie. Cohesion and coherence in situational context and discourse. Journal of Ocean University of China (Social Science), 2006(1):44-47. 
[2] Wei Xuechun. Application of discourse cohesion and coherence theory in English reading. Decision \& Information (midmonth), 2015(12):106.

[3] Hu Zhenying. Application of discourse cohesion and coherence in English-Chinese translation. China Electric Power Education, 2010(16):192-195. 